\title{
Convenience and Uniformity in Reporting Norms for School Tests
}

\section{J. Crosby Chapman}

To cite this article: J. Crosby Chapman (1922) Convenience and Uniformity in Reporting Norms for School Tests, The Journal of Educational Research, 5:5, 406-420, DOI: 10.1080/00220671.1922.10879269

To link to this article: http://dx.doi.org/10.1080/00220671.1922.10879269

曲 Published online: 15 Dec 2014.

Submit your article to this journal \lceil

Q View related articles $₫$ 


\title{
CONVENIENCE AND UNIFORMITY IN REPORTING NORMS FOR SCHOOL TESTS
}

\author{
J. Crosby Chapman \\ Yale University
}

The desirability of securing some uniform procedure for scaling the achievements of pupils in school tests is evidenced by the recent attempts and suggestions which have been made by several authors. Reference may be made to the work of $\mathrm{McCall}^{1}{ }^{1}$ Pintner, ${ }^{2}$ Buckingham, ${ }^{3}$ and Buckingham and Monroe. ${ }^{4}$ These very recent papers indicate the extent to which trained workers in this field realize the necessity for some definite conventions. For the larger number of individuals without much training, who are using these tests in practical work, there is even more necessity for definite agreement. An association such as this journal represents could hardly fulfil its function better than in furthering this attempt to secure uniformity and order, in a situation which as it now exists is chaotic.

At present a score of twelve in one test means the same level of achievement as fifteen, thirty-five, or seventy-one in another test. Even after we have transmuted from the crude scores to equivalent scores, there is again no uniformity. A score of fifty may mean the median achievement of unselected twelve-year-olds, as in McCall's plan, or the median achievement of an unselected group of any age as in Pintner's procedure, or the achievement of a particular mental age as in the method of Monroe and Buckingham.

We must work for an agreement whereby after the transition has been made from the crude score to the equivalent score, the latter will have an obvious meaning. This meaning must be

'MeCall, William A. "A uniform method of scale construction," Teachers College Record, 22: 31-51, January, 1921.

${ }^{2}$ Pintner, Rudolf and Marshall, Helen. "A combined mental-educational survey,"' Journal of Educational Psychology, 12: 32-43, January, 1921.

'Buckingham, B. R. "Suggestions for procedure following a testing program,"'Journal of Educational Research, 2: 787-801, December, 1920.

'Buckingham, B. R. and Monroe, Walter S. Illinois Examination, Teachers Handbook, 1920. 
simple, and above all it must be expressed in terms immediately applicable to the practical uses to which tests are put by schoolmen. The present almost complete lack of uniformity in reporting standards is unquestionably complicating and in many cases preventing the use of educational scales in the schools.

Binet and Terman have fulfilled the above requirements in the field of mental measurement. Perhaps, as is indicated later, their method of reporting mental ages has sacrificed too much to the desire to be readily interpretable by the layman, but they have at least used a very simple unit of measurement. Possibly the wide use of intelligence scales is partly explained by the obvious interpretation of their results. ${ }^{5}$ It is certainly not too much to ask, that in the near future a somewhat similar uniform procedure may be adopted in the field of educational measurements.

McCall makes the plea that all tests be standardized and the equivalent scores be expressed in terms of an adapted sigma distribution of unselected twelve-year-olds. Involving as it does a continuous scale; many advantages are at once derived from such a procedure; these are well summarized in his article. In discussing some of the weaknesses of his proposal, these merits must not be overlooked. The following disadvantages must, however, be given careful consideration. Some of them, in the opinion of the writer, are sufficient to prevent his procedure from being adopted in school practice.

(I) It is impossible to scale even the moderately low performances of the lower grades, and the high performances of the upper grades. This is because the data for twelve-year-old pupils become so extremely attenuated or non-existent as to make any scale score unreliable, or impossible to determine.

(2) McCall's basic assumption is very much open to dispute. This is that however irregular a distribution of the twelve-yearold population may be, the distribution of all the other age populations is exactly, or within reasonable limits, the same. While

\footnotetext{
- At least it appears obvious on the surface; this obviousness disappears on closer analysis.
} 
such an assumption may well be true for tests which are very carefully constructed, and for tests which measure some skill such as reading ability by material which is easy for the lowest age population considered, it is more than doubtful whether the assumption holds for tests which are less carefully assembled, and for tests which measure informational material rather than some basic skill of steady growth.

(3) There will be a natural tendency on the part of the casual user of tests so standardized to assume, for a particular group, other than twelve-year-olds, that forty on the scale for one test is really the equivalent for that group of forty on the scale for any other test. Great practical advantages would be derived from any scheme so constructed that, for any particular group considered, a score of forty would mean the same level, with respect to that group, in any test, just as in McCall's scale a score of fifty or any other score means the same, for the twelve-yearold population, in every test. Owing, however, to the differences in overlapping of any two groups in different tests a score of forty on his scale in one test would be attained by $x$ percent of a particular population, other than twelve-year-old, while the same score in another test would be attained by a quite different percent. Thus while a scale score of $t$ units means the same, irrespective of the test, for twelve-year-olds, it would not have the same meaning for any other population.

(4) There seems something incongruous in standardizing tests, covering material taught in Grade VIII or VII, on a population of which a considerable portion has not been subject to instruction. This point will be returned to later.

(5) There is the less academic but more practical question as to whether the school people who give the tests are not more interested in thinking in terms of grades, that is in placing a child in a particular group, than in discerning his position on a scale calibrated with an unselected group of twelve-year-old pupils. Usually the question is one of promotion, or transfer to some other group. Where the thinking is done in terms of grades there is a great advantage in having the median and other per- 
formances of each grade in some constant term. While unquestionably as far as grade seven is concerned the median performance on the McCall scale will be approximately fifty, for all the other grades, the standards and achievements of the various levels will have to be expressed in units which will be by no means self-evident. Thus a score of thirty when made by a fifth-grade child will not carry its meaning on its face; it will only, after reference to further tables, tell us how he stands in his own grade.

For purposes of standardizing new tests, there are great advantages in McCall's method, but for convenience of use in the schools, it would seem that a method centering around grades has very distinct advantages. Of course McCall's scale could again be turned into levels of achievement at the various grades. For the schoolman, however, this is a gratuitous intermediate process.

Pintner has employed almost the same method as McCall, but instead of using a single age group, he uses all the unselected age and grade groups. He also is guilty of pressing his data beyond the point at which reliability can be obtained.

Furthermore, while the small word "unselected" can easily be inserted as a requirement in the standardization process, an unselected age group is irksome to secure, whereas an unselected grade is usually to hand waiting to be tested. While unquestionably the age group is slightly more stable and more constant than the grade group, it may still be more practically advantageous for McCall to use an unselected mid-year grade group such as Grade VII than an age group. The burden of proof rests upon those who advocate the use of unselected twelve-year-olds that this gives any added advantage commensurate with the administrative difficulty of securing such a group.

For we cannot too often warn ourselves not to go to too much trouble to standardize. We are always standardizing our test by a criterion which we trust is changing. In other words, we design our tests as part of a larger movement which it is hoped will change the conditions themselves by which we standardize. It is 
as though in a cold country where there are no thermometric standards we should attempt with elaborate minuteness to standardize the points on our scale by taking at a particular period of time the average temperatures of a large number of dwellings, simultaneously starting a movement, with the help of the scale thus standardized, to raise the average temperature of the houses. The more effective the movement and the more our scale hastened the change, the more impossible it would be to maintain anything more than a rough standard of temperature. To select our houses too carefully or to spend much time in calibrating our instrument by such a criterion would obviously be absurd. Now this is the exact state of affairs with certain of the scales. Thorndike and $\mathrm{McC}$ all recommend their reading scales as devices for improving the objective product; yet it is by this product, a changing factor, that they propose to standardize the scale. For rough estimates no doubt this procedure is justifiable, but it shows how easily too much time may be spent in elaborate standardization. All this is pertinent to the question as to whether an age group which is difficult to procure, furnishes a sufficient amount of increased stability to justify its use.

There is of course no need, when considering the relative merits of age groups and grade groups, to decide exclusively in the favor of one or the other. Both are essential. This paper makes the plea that, all things considered, the grade group is not only more convenient but also more significant in school practice and school thinking. Age groups will, however, have to be used for many purposes and, suggestions are later made for a uniform scheme of presenting results for such groups, similar to that suggested for grade groups. For example, in the matter of intelligence we have every right to think in age groups. Probably the best procedure is to place a child in each age group, and make no attempt to refer him to groups that have had more or less years of environmental experience. Any such comparison is perilous at best. This point is taken up at fuller length in an experimental study on "A Further Criterion for the Selection of Mental Test Elements."

- An article to appear in the Journal of Educational Psychology, May, 1922. 
It is quite apparent that if the passage is to be made from crude scores to achievement quotients, based on mental age, one must work with age groups. Such passage will, however, if it is to be at all reliable, necessitate very accurate instruments which measure very specifically the two factors involved, namely school achievement and mental achievement. The present attempts in this ambitious direction, involving as they do all the errors characteristic of both types of measurement must be taken cum grano salis. Especially is this true when the very tests by which we measure school efficiency are themselves being used with satisfactory results by other experimenters, to measure the other variable-namely, intelligence itself. Thus, for example, the National Intelligence Test employs a fundamentals test as a measure of intelligence. Pintner ${ }^{7}$ using a non-linguistic test is less subject to criticism than Monroe and Buckingham; but a careful consideration of the inaccuracy of the two measurements, intelligence and school achievement, together with the fact that we are certainly measuring to no small degree the same factors, should make us very careful in interpreting such results at their face value, for the individual pupil.

The same criticism regarding reliability applies to the work of Monroe and Buckingham in the Illinois Examination. Here crude scores are transmuted into achievement ages, from which they pass to achievement quotients. To overcome the difficulty that the high scoring pupils in the higher grades score more points than the norms for thirteen and fourteen years, the authors are compelled to resort to the hypothetical achievements of age groups which cannot be obtained empirically. This extrapolation is carried almost to the limit when for a particular crude score in arithmetic we find on transmuting it into achievement age that it corresponds to a performance of 25 -year-olds.

" Pintner says that for 300 children, ranging from the third to the sixth grade a correlation of .47 was obtained between his mental index and the $I$. $Q$. on the Stanford-Binet. For the purposes for which he uses his indices, even allowing for the unsatisfactoriness of the Stanford-Binet as a perfect criterion, it seems hardly justifiable, considering the range of the group tested, to say, as he does, that such a relationship is "very satisfactory." If there is the same unreliability for the educational index the ratios must be exceedingly unreliable. 
The significance and accuracy of such achievement ages, dependent as they are on assumptions with reference to the normality of distribution or upon extrapolation are much open to question. Seeing that there is so much difficulty in determining the standard scores, for a random group of (let us say) twelveyear-olds, which actually exists and can be subjected to testing, it would seem that any device which demands assumptions with reference to the scores of seventeen and eighteen year groups, could hardly be considered a permanently satisfactory solution. Moreover, there is again the difficulty in interpretation. In considering the achievement in an arithmetic test, how few of us are helped at all by saying that two performances are separated by an amount characteristic of the difference between sixteen year and twenty-three year old standing.

Buckingham ${ }^{8}$ has made the suggestion that in the attempt to procure ease of interpretation we should call, by agreement, the median achievement of Grades VIII, VII, VI, etc., 8, 7 and 6 respectively. While this procedure is attractive in its simplicity, it suffers from the great drawback that it is impossible to refer the high scores of Grade VIII and Grade VII to any standard; they exceed 8 and we can only have by doubtful extrapolations a 9, IO, II, or I2, for hypothetical groups. The suggestion of this present paper is to combine some of the merits found in the devices of McCall, Buckingham and Pintner, particularly the last, with certain other factors to accomplish the end of securing an obvious interpretation of any transmuted score, expressed in terms which make it readily applicable to the school and administrative situation. This suggestion is to transmute the crude scores of the test, into the mid-year distributions of the various grades.

This procedure will be made evident by reference to Table I which was obtained from limited data on the four tests comprising the Chapman Class Room Products Test. ${ }^{9}$ In this examination battery the four tests are: (I) arithmetic fundamental

${ }^{8}$ Buckingham, B. R. "'Suggestions for procedure following a testing program,' Journal of Educational Research, 2: 787-801, December, 1920.

- Published by the J. B. Lippincott Company. 
(A F); (2) arithmetic problems (A P); (3) reading selections (R S); (4) reading continuous ( $\mathrm{R} \mathrm{C}$ ). For each of these tests and for the total for Grade V, VI, VII, VIII the achievement at mid-year for the nine equally increasing (with generous assumptions!) levels, o.4 sigma apart, are shown. These levels are given the descriptive designation shown in the first column, and the quantitative designation ranging from $I$ to 9 , shown in the second column. Whether mid-year or end-year standards are chosen is a matter of agreement. For tests of skill which are the result of long training, the former is advantageous; for tests of informational material which is acquired in a single grade the end-year standard is referable. Assuming mid-year standards as given, suppose a pupil in Grade VI scores on the total test 47 points. By referring to Table $I$, it is possible to determine the levels of achievement for Grade VI, VII or VIII. In the case considered, it will be seen that the particular pupil's achievement is sixth-grade high or VI-7. This will be the usual status wanted. Where, however, for purposes of regrading the desire is to discover the place of the pupil in Grade VII or Grade VIII, it can be readily seen from the table that his score corresponds to seventh-grade median or VII-5, and to eighth-grade medium low or VIII-4. This illustration brings out an important merit of the proposed system of reporting. Those who are working in the schools with these measuring instruments are trying to break down certain ideas concerning the present system of grading, particularly the notion that a grade represents a narrow level of achievement of a homogeneous group. The most powereful instrument to employ in attacking this problem is one which shows on its surface the extent to which overlapping of the grades is present. This the suggested system is well calculated to accomplish; for when the transition is made from the crude scores to the equivalent scores, a momentary examination of the table shows that the same crude score may be characteristic of different levels of achievement in different grades. The proposed scheme focuses attention upon grades and the wide range of achievement in a grade, rather than on a distribution in terms of 


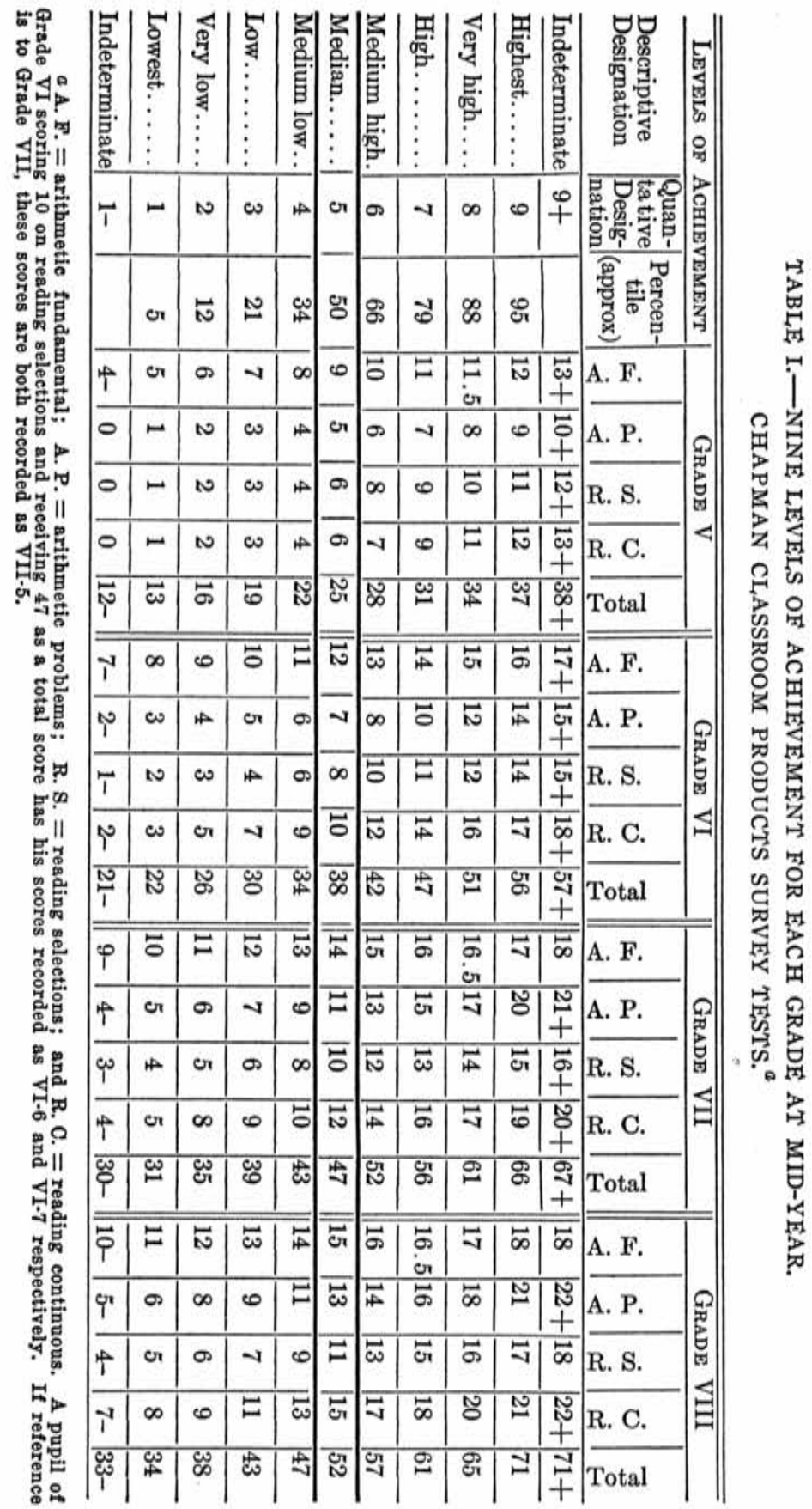


a single population. Of course, the wide variations of achievement on the continuous scale show the same thing, but do they show it as obviously? We have already made the point that the thinking of the practical schoolman is in terms of grades, and that eventually children, as the result of the tests, have to be placed in grades. There is, however, a further reason why standardization by grade groups rather than by age groups should be given preference. This is found in the fact that the subjects in which we test are taught by grade rather than by age. By this is meant that a certain part of history or civics is taught to Grade VII and Grade VIII and not to I3- or I4-year-old groups. It seems disadvantageous to use as the standardizing group a population such as McCall's of which a considerable portion have never been exposed to the instruction in the elements out of which the test is constructed. While this criticism applies much less to examinations in reading, and to wide examinations in arithmetic, yet in specific elements in arithmetic taught in later grades it is certainly very pertinent.

We shall make no attempt to pass above the 95 percent point which is called 9 , because the data, unless originally very great in amount, are becoming so attenuated at this point that reliability is out of the question. ${ }^{10}$ Where the score passes beyond that of the $5^{\text {th }}$ or $95^{\text {th }}$ pupil at the extremes, it may well be left indeterminate, calling it $\mathrm{I}-$ or $9+$. To refuse to pass beyond these points and to leave the rating indeterminate if less satisfying is at least an intellectually honest procedure.

For each grade there are thus nine levels each separated by equal amounts. These for any particular grade, such as VI, are written VI-I, VI-5, VI-9, etc. Together with the indeterminate levels, VI-I - and VI-9 +, there are thus eleven levels for each grade. If the data are sufficiently homogeneous and extensive to justify the process, we may insert intermediate steps with suitable descriptive terms and with quantitative designation, e. g., I.5, $2.5,3.5$, etc., up to 8.5 . This would furnish nineteen levels of achievement.

${ }^{10}$ Yule, G. Udney. An introduction to the theory of statistics. (Fourth edition.) London: Charles Griffin and Company, p. 341. 
When very fine correlation work has to be done with the transmuted scores, it will of course be necessary to work to smaller limits than those afforded by the eleven or even the nineteen levels. This however will be a simple matter of interpolation and extrapolation. We can readily decide not only the achievement of VI-5 or VI-6, but also the achievement of VI-5.2, VI-5.3 or VI-5.4.

When dealing with an extreme case falling beyond the equivalent of 9 for a particular grade, it is surely better to pass to a higher group and place the case in that, than to rely on very inaccurate points at the end of a distribution, as McCall is compelled to do. If a pupil in Grade VI falls in VI-9 +, it is obvious that he is out of place, and that by referring to the distribution of the higher grades, we can see where he fits. If, however, we are giving tests to measure improvement, the scores of the few pupils at the two extremes would have to be given special treatment.

When it is desired to work in age groups, the same procedure as that above advocated would be recommended. Here the prefix would be in Arabic instead of Roman numerals, e. g., I2-5 would indicate the median achievement of unselected pupils in the neighborhood of 12 years old. Roman figures would always indicate grades, and Arabic figures would indicate ages. Meanwhile, seeing that almost all thinking takes place in grades, particularly when the problem is that of regrading, it is well to establish the grade norms first rather than the age norms. If, however, we wish to make comparisons from country to country, there is much to be said for age norms. Certain English writers, for example Ballard, are making the appeal for age norms for the simple reason that they do not understand the American grading systems.

In the matter of intelligence tests where primarily the thinking is done in age groups, the above convention would also apply. The Arabic figures would represent the age and the figure following would indicate the level of achievement. In certain cases where the measures of intelligence were very reliable, it might 
be necessary to establish by interpolation or experimentally intermediate achievements. For example for pupils ro years, 6 months the designation might be 10.5-7.

The same convention as to grades could be extended beyond the elementary school, the various years of high school being given the designation IX, X, XI, and XII, and the corresponding levels for each high-school subject determined.

When the main interest is in measuring improvement, particularly over short spaces of time, rather than in regrading, the equally spaced steps of any of the various grade levels may be used. Other things being equal, grade VII levels would probably give the most useful system of units. In those cases where the desire is to measure over a longer period, say a number of years, two alternatives present themselves. In the first place, we may measure the improvement discontinuously in terms of the different grade levels. An advancement from VI-5, to VII-5 would represent a year's improvement, in the same way as an advance from VII-7 to VIII-7 would represent, neglecting selection, a normal year's growth. In fact, when measured in these terms ease of interpretation and usefulness of information are at a maximum; for when merely grade averages are reported, as a test is repeated from year to year, little attention is given to those that exceed the average, largely because there is no ready method of checking up their degree of improvement. When, however, we have the various levels for the different grades established, interpretations of degrees of improvement of pupils far removed from the median will be readily possible. Thus a score increase from VI-9 to VII-9, will be just as good for a pupil of the nine level, as a jump from VI-5, to VII-5 will be for a pupil of the median level.

If, however, a continuous scale is demanded-and physical measurement suggests that in those few tests which are applicable to a wide range of grades, such a scale is the ideal-I would suggest that we use the total population of grades five to eight, employing unselected children at mid-year from these four grades in equal number. Considering these groups as a single population, 
we may determine the nine levels, or for finer grading the nineteen levels, in the same way as with a single grade group. It would be necessary to have some designation for such a series of steps. Perhaps U. S. might be used, the letters standing for "Universal Scale."

Such a combination of 100 unselected pupils from each of the four top grades at mid-year has been made for the above mentioned test, with results as shown in Table II. This combination of 400 is treated as a single group, and the nineteen levels of achievement in the totals of the four tests are exhibited. In this way we get a scale which is continuous in the same way as McCall's but which is less subject to the censure that extreme scores cannot be scaled. Furthermore, it is derived from a population which can readily be obtained for testing purposes. Only in a few of the wider tests, reading par excellence, could this broad population be used. Otherwise the procedure would be subject to the same criticism as is McCall's, in that we should be standardizing our scale on a population a large section of which had been given very little or even no chance to score in the test. The fact that in the narrower tests we are compelled to use short scales, which, so to speak, break at various points, is probably inherent in our problem. The physical analogy of the yard stick, while suggestive, is not really applicable. There is continuity, for example, in height within any group, say twelve-year-olds; but the same is not true for knowledge of civics, or of interest in arithmetic. Here we strike the problem of the undistributed zero.

To avoid misunderstanding, it is perhaps well in closing to point out explicitly two demerits of the universal scale procedure. The first is found in the experimental fact that grade groups are less constant than age groups in achievement. This is caused by differing procedures with reference to promotion from system to system. The second disadvantage is that in dealing with grade groups, standardization must take place at some definite point in the history of the grade, presumably either at mid-year, or at end-year. In contrast to this limitation, standardization by age 
May, 1922 CONVENIENCE AND UNIFORMITY FOR SCHOOL TESTS 419 groups can in the general case be done at any time. Neither of these drawbacks is sufficient to prevent the procedure from being used. The first point has already been met; whatever norms are obtained will always be subject to greater inaccuracy than will be produced by varying standards of promotion. Probably care

TABLE II.-A UNIVERSAL SCALE ${ }^{a}$

\begin{tabular}{|c|c|c|c|}
\hline $\begin{array}{l}\text { Descriptive } \\
\text { Designation }\end{array}$ & $\begin{array}{c}\text { Per- } \\
\text { CENTILE } \\
\text { (approx.) }\end{array}$ & $\begin{array}{l}\text { QUANTITATIVE } \\
\text { Designation, } \\
\text { EqUIVALENT } \\
\text { Score }\end{array}$ & $\begin{array}{l}\text { Crude } \\
\text { Score }\end{array}$ \\
\hline $\begin{array}{l}\text { Indeterminate } \\
\text { highest.......... }\end{array}$ & . & US-9+ & $68+$ \\
\hline \multirow[t]{2}{*}{ Highest. . . . . . . . . } & 95 & US-9 & 67 \\
\hline & 92 & US-8. 5 & 63 \\
\hline \multirow[t]{2}{*}{ Very high......... } & 88 & US-8 & 60 \\
\hline & 84 & US-7.5 & 57 \\
\hline \multirow{2}{*}{ High............ } & 79 & US-7 & 53 \\
\hline & 73 & US-6. 5 & 50 \\
\hline \multirow[t]{2}{*}{ Medium high...... } & 66 & US-6 & 46 \\
\hline & 58 & US-5.5 & 43 \\
\hline \multirow[t]{2}{*}{ MEDIAN . ....... } & 50 & US-5 & 40 \\
\hline & 42 & US-4.5 & 37 \\
\hline \multirow[t]{2}{*}{ Medium low....... } & 34 & US-4 & 34 \\
\hline & 27 & US-3.5 & 31 \\
\hline \multirow[t]{2}{*}{ Low.............. } & 21 & US-3 & 28 \\
\hline & 16 & $\mathrm{US}-2.5$ & 25 \\
\hline \multirow[t]{2}{*}{ Very low $\ldots \ldots \ldots$} & 12 & US-2 & 23 \\
\hline & 8 & US-1.5 & 21 \\
\hline Lowest. . . . . . . . . & 5 & US-1 & 18 \\
\hline $\begin{array}{c}\text { Indeterminate } \\
\text { lowest........ }\end{array}$ & & US-1- & $17-$ \\
\hline
\end{tabular}

$a$ Totals in the Chapman Classroom Products Tests at the various levels. Popula. tion, 100 unselected pupils from each of Grades V to VIII. A pupil scoring 53 is recorded as US-7. 
will have to be taken to secure standardization material from school systems in which the age-grade tables are reasonably normal. The second point raises a real difficulty but not as great as that which will have to be met in combining age groups, a procedure to which I believe, McCall will have to resort if his scale is to be at all reliable at the extremes. To secure unselected twelve-year-olds is within the bounds of possibility, but the higher unselected age groups can probably not be attained and the low unselected age groups will bring in the problem of the undistributed zero.

\section{Summary}

This paper presents a scheme of reporting test scores whereby, after the transition has been made from the crude score to the equivalent score, the latter bears, upon its face, an obvious and useful interpretation.

Nine equally separated levels of achievement for each grade are set up. These levels for a particular grade being referred to as VI-4, VII-8, etc. In addition to this quantitative rating, these nine levels are given a descriptive designation.

For age groups, the same method of report applies, Arabic numerals replacing the Roman numerals.

Intelligence levels at all ages admit of treatment by the same method.

Where a continuous scale is demanded, the mid-year GradeVII scale is suggested. If this is not wide enough, an unselected population consisting of the four top grades (at mid-year) in equal number is recommended. This is treated as a single group and the same nine levels determined. If the data are extensive, these nine may be extended to seventeen or much further. The designation for a level of such a group is US-5, US-8, etc.

In every case the figure or letter before the hyphen signifies the group to which reference is made, the figure after the hyphen indicates the level attained. 